\title{
Conceptual Design and Finite Element Fatigue Life Analysis of a Poppet Valve Spring Compressor
}

\author{
Anthony Simons $(\mathbb{D}$, Gideon Quartey, and Nathaniel Frimpong Asante \\ Department of Mechanical Engineering, University of Mines and Technology, Tarkwa, Ghana \\ Correspondence should be addressed to Anthony Simons; asimons@umat.edu.gh
}

Received 18 May 2020; Accepted 20 July 2020; Published 17 August 2020

Academic Editor: Kevser Dincer

Copyright (c) 2020 Anthony Simons et al. This is an open access article distributed under the Creative Commons Attribution License, which permits unrestricted use, distribution, and reproduction in any medium, provided the original work is properly cited.

In the overhauling of the internal combustion engine, a lot of tools are used and among them is the poppet valve spring compressor. In Ghana, auto mechanics at the "way-side" garages make use of improvised tools, such as pipes, pliers, and push rods, for compressing valve springs. However, there are some challenges associated with the usage of these tools which include misplacement of cotters, injuries, and sometimes valve bends. In this work, a review of some of the existing designs of the improvised tools was considered. Also, a survey was conducted to seek the opinion of users (auto technicians and/or mechanics) of the tools. A design was made for spring compression by incorporating a magnet with a pull force of $679.78 \mathrm{~N}$ to take care of the removal of cotters during valve assembly dismantling. In this research, an efficient and user-friendly poppet valve spring compression tool with a total mass of $0.88 \mathrm{~kg}$ was designed. Finite element analysis (FEA) was performed on the upper and lower parts of the tool to examine its response due to the loads that act on it during operation. It was discovered from the analysis that the upper frame of the valve spring compressor experienced the highest von Mises stress of $59.77 \mathrm{MPa}$ at the neck region, whilst the corresponding fatigue analysis showed a maximum fatigue life of $8.355 \times 10^{9}$ cycles.

\section{Introduction}

The poppet valve found in the cylinder head of internal combustion (IC) engines helps regulate the flow of gases (fuel-air mixture and exhaust gases) either entering or leaving the cylinders. The poppet valve is either press fit or interference fit in the cylinder head, and sometimes, it is made integrated with the cylinder head. The valve is held down to its seat by one or two coil springs, while one end of the spring is located on the cylinder head or block casting and the other is by a spring retainer cup [1]. There are two collets made of steel, which are used to attach the spring retainer cup to the stem of the poppet valve with the help of a groove made in the valve stem and the conical shape of the outer surfaces of the collets. This ensures that the valve spring always holds the valve in the required position [2]. The connection between the valve retainer caps and the valve is secured by valve cotters as shown in Figure 1.

During engine overhauling, the removal of the poppet valve (the overhead valve arrangement) from the cylinder head becomes difficult using the existing improvised valve compression tools. External accessories such as the human fingers, screw drivers, and magnets are needed. The cotters are mostly removed using a screwdriver together with the valve removal tool. In the course of the removal, the cotters may fall into the oil ducts of the cylinder head or may fly off, thereby causing either injures to the technician or get lost eventually. In maintenance, safety is the foundation of every activity in anything that causes human pain which should not be tolerated, and safety culture must continuously be improved. Therefore, this project was to design a poppet valve spring compressor to make the removal of poppet valves easy and safe.

\section{Existing Methods of Valve Spring Compression}

In Ghana, the way-side mechanics have different means of removing the poppet valve from the cylinder head in the course of engine rebuilding. These mechanics do not have 


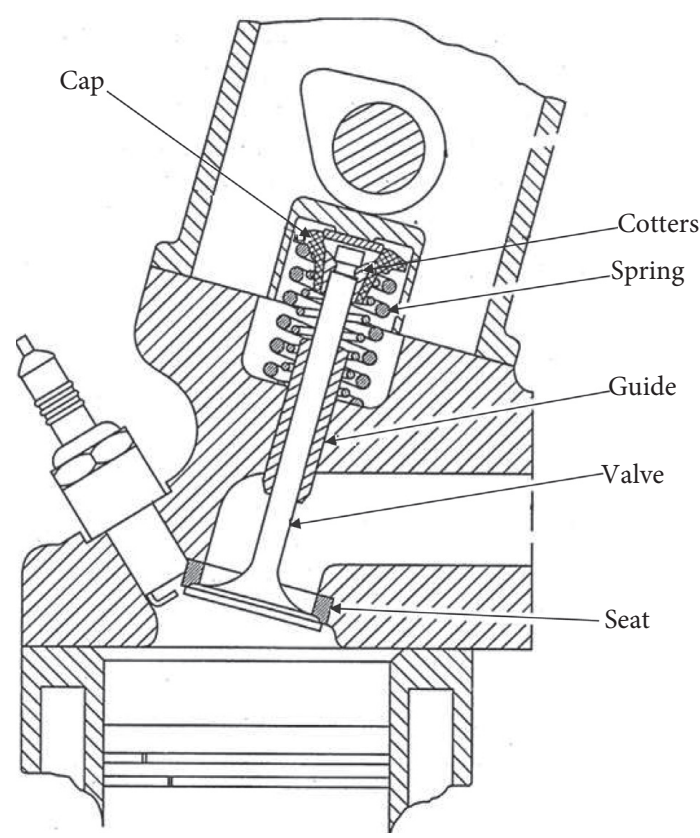

Figure 1: A section of an IC engine showing a poppet valve assembly (Source: [3]).

standard tools for their maintenance activities. Some of the improvised tools they make use of are hollow pipes, pliers, and push rods as depicted in Figure 2. The problems associated with the usage of these tools are as follows: mechanics usually get hurt by flying cotters, and valves are damaged in the process of removal and cotters get lost.

\section{Research Survey}

To ascertain the risk associated with the usage of existing valve spring compression tools, a quantitative survey was piloted within a homogeneous sample space of two locations: Accra and Takoradi, with a population target of fifty (50) persons per location. The survey process selected for this project was a combination of a simple random sampling for the selection of homogeneous workers and judgemental sampling in the case of location selection. Figure 3 depicts the difficulties encounted by mechanics when compressing valve spring.

It was observed that $31 \%$ of the respondents had difficulties with the kind of strength needed to operate the tools they use in compressing valve springs. $22 \%$ of the respondents stated that they use other accessories such as magnet and screwdriver to assist them in removing the valve assembly, and $44 \%$ had problem with the misplacement of cotters during the removal of the valve, whilst $2 \%$ complained of cotters breakage as a result of wrong choice of tools.

From Figure 4, 26.32\% of the respondents suggested incorporation of an inbuilt magnet in the existing tools, and $25.79 \%$ wished that they have an ergonomic tool. Those respondents who recommended the use of less power when using the tools form $20.52 \%$. Furthermore, $17.37 \%$ of the mechanics wished that slippage of tools during work could be avoided, whilst $10 \%$ of the respondents suggested that further improvement should be done on the improvised valve spring compression tool to make it effective and safe for work.

From the survey conducted, it could be concluded that it is imperative to design a user-friendly device to help auto mechanics to overcome the challenges they face.

\section{Proposed Design}

The proposed design (Figure 5) has two major parts (the upper frame (1) and the lower frame (7)), which are both made of plain carbon steel. The upper part has a handle which is inclined at an angle of $60^{\circ}$ (for gravitational force to aid its operation) and houses the pressure disc unit (4). The pressure disc unit has a cylindrical hollow magnet (3) found in an externally threaded nonferromagnetic case (2). This is to enable the magnetic hollow disc to be replaced by a larger internal diameter type in case a larger valve tip diameter is to be worked on. The lower frame has a pivot which joins the upper frame to it through a pivoting pin (5). Another feature of the lower frame is an integrated fork, which slides in between the gaps of the spring where the stem of the valve positions itself in between the two fingers of the fork as the centre of the cross section of the valve stem aligns with the centre of the hollow magnet. There is one other pin (6), fixed on both fingers of the upper frame, that holds the pressure disc to the upper frame.

Present in this design are all the components necessary for a complete dismantling of poppet valve assembly without the use other accessories, which are employed when using the existing improvised tools. This design has the ability to restrain the cotters from flying off during valve spring compression. This is achieved with the aid of the incorporated magnet, which attracts the cotters when they become loose from the valve assembly. Consequently, the cotters are prevented from getting lost, and users are protected from being injured by flying cotters. Again, the device is more productive and user-friendly than the existing improvised tools in Ghana.

\section{Principle of Operation}

The compression of the spring is performed by pulling down or drawing the handle, which is attached to the upper frame (1) downward. Since the upper frame is pivoted to the lower frame (7), the pressure disc unit (4) presses on the spring retainer, which transfers the force from the handle through the upper frame to the spring for compression. The retainer moves down away from the wedge of the cotters where by the tip of the valve stem together with the cotters enters the hollow magnetic cylinder (3) which intend attracts the cotters to itself due to the magnetic force, which overcomes the weight of the cotters. After the spring compression, the handle is slowly lifted away from the spring, and the valve is easily removed from the cylinder head. 


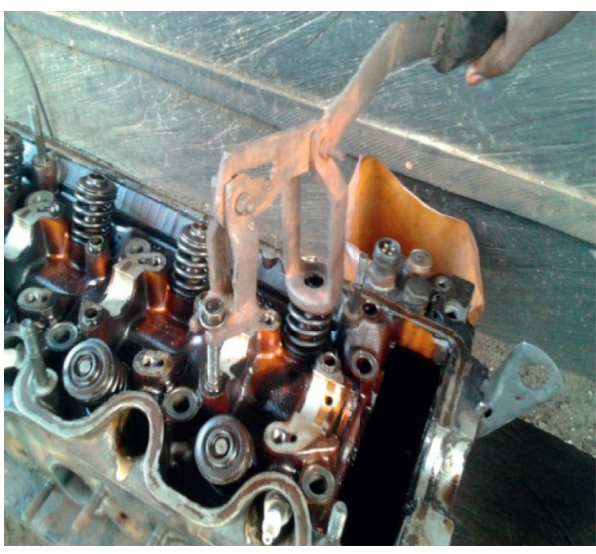

(a)

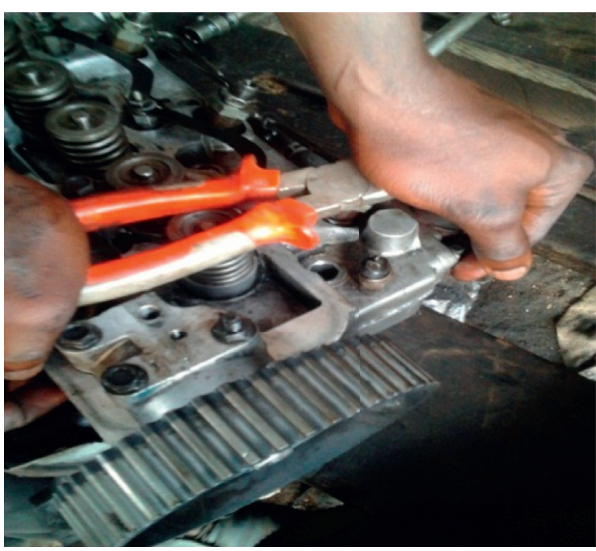

(c)

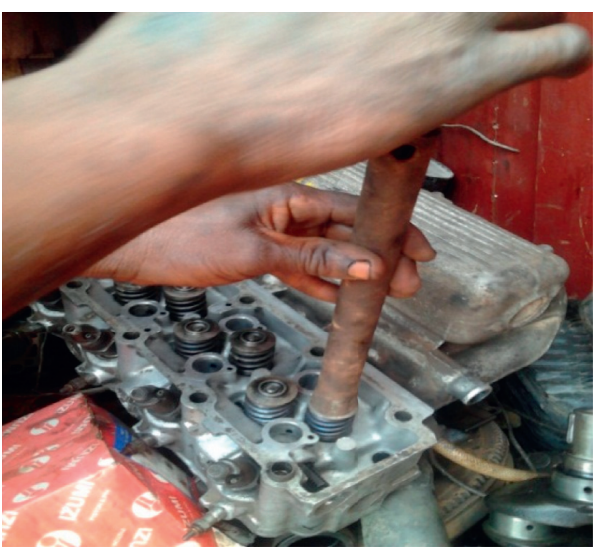

(b)

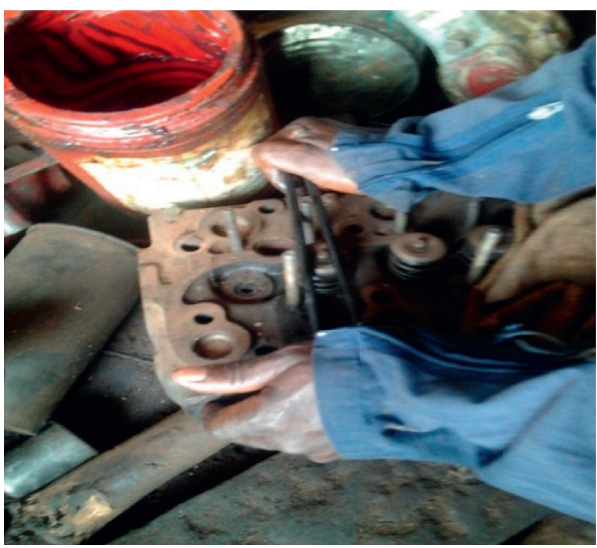

(d)

FIGURE 2: Methods of compressing valve spring. (a) Invented tool for spring compression. (b) Hollow pipe mostly used with a hammer. (c) A pair of pliers for spring compression. (d) Push rods as spring compressor.

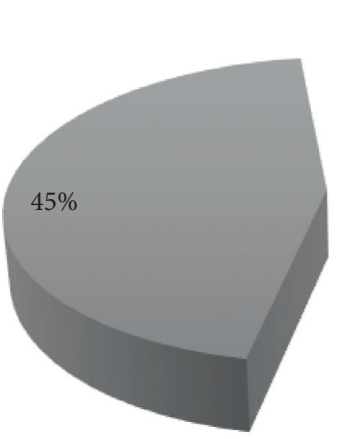

- Too much strength needed to operate

External accessory needed

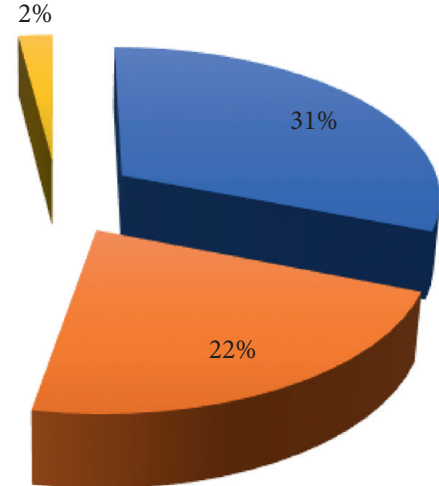

Misplacement of cotters

- Others

Figure 3: A pie chart of the difficulty involved in the valve removal. 


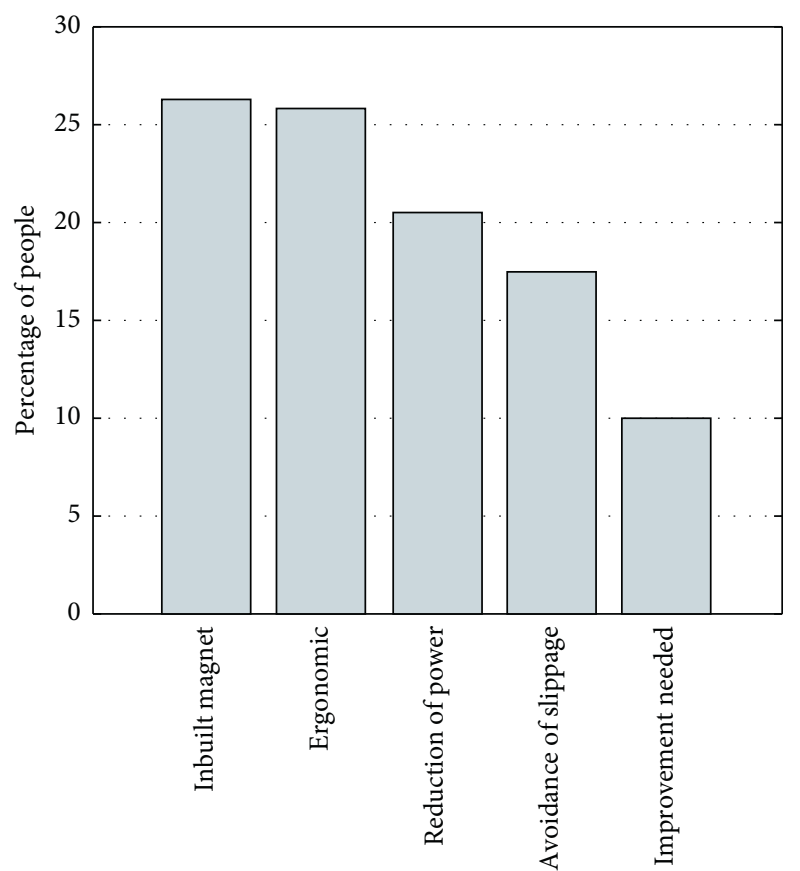

Figure 4: Recommendations to improve the existing tool.

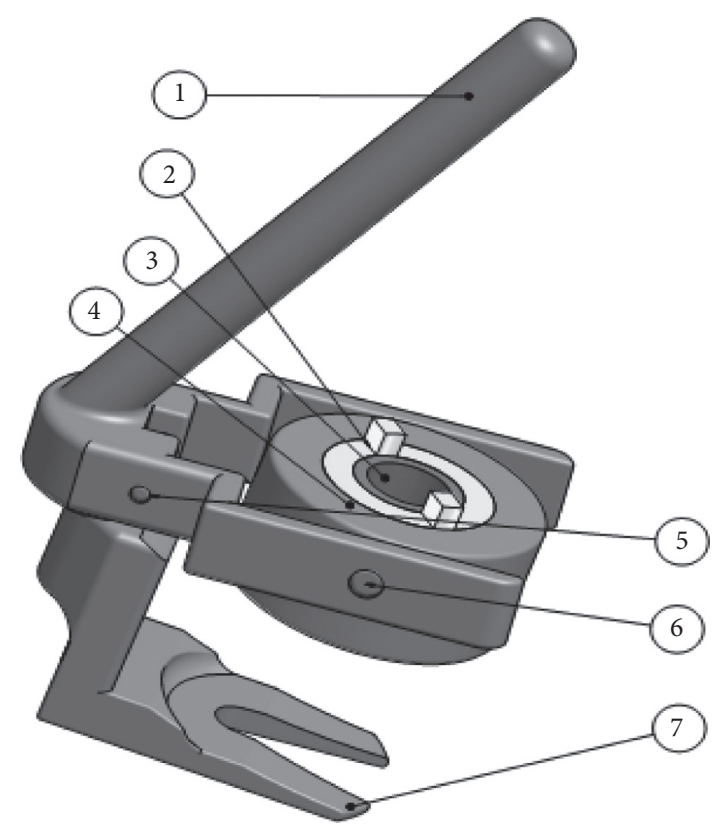

Figure 5: Proposed design of a poppet valve spring compressor.

\section{Design Calculations}

Design calculations were computed in the following areas to determine some parameters including bending and shearing stresses, bending moment, shear force, and magnetic pull force. These aided in the design of handle and pivoting pins. Considering the material properties and a light weight device, a safety factor of 2 was used for design calculations.

Spring force $(F)$ can be expressed as

$$
F=k x \text {, }
$$

where $k$ is the spring constant and $x$ is the displacement.

Valve spring force of a racing vehicle was used for the computation. This was because in high performance racing engines, very stiff valve springs are typically used to achieve higher engine speed without the valves floating [4]. If racing vehicles' valve springs can be compressed with this tool, then it is possible for the tool to be used on almost all other vehicles. From the Peterson American Company (PAC) racing spring master catalogue, a spring type of single standard with the part number of PAC-1906, having a spring constant $(k)$ of $291 \mathrm{~N} / \mathrm{mm}$ with a maximum deflection $(x)$ of $3 \mathrm{~mm}$ was chosen for the computation. From (1), the spring force $(F)$ was calculated to be $873 \mathrm{~N}$.

From Figure 6, $F_{A}$ is the horizontal force acting on the pin joint, $F_{B}$ is the vertical force acting on the pin joint, $F_{S}$ is the spring force, $F_{W}$ is the weight of the pressure unit, and $F_{C}$ is the applied force. The unknown forces, $F_{A}, F_{B}$, and $F_{C}$ were determined as $-334.632 \mathrm{~N},-676.3 \mathrm{~N}$, and $386.4 \mathrm{~N}$, respectively.

The major modes of failure of the device are bending and shearing. Therefore, the handle and the pivoting pin should be able to withstand the bending and shearing stresses. The bending moment and shear force diagrams are shown in Figure 7 .

Transverse shear stress $(\tau)$ for rectangular cross sections can be expressed as

$$
\tau=\frac{3 V}{2 A}
$$

where $A$ is the area of a rectangular cross section, and $V$ is the shear force.

Maximum bending stress for rectangular cross sections $\left(\sigma_{r}\right)$ is computed as

$$
\sigma_{r}=\frac{6 M}{b h^{2}}
$$

where $M$ is the moment, $b$ is the base, and $h$ is the height.

From maximum shear stress $\left(\tau_{\max }\right)$ theorem, maximum shear stress in the member is equal to

$$
\tau_{\max }=\frac{S_{y}}{2 n},
$$

where $S_{y}$ is the yield strength of the material and is equal to $324 \mathrm{MPa}$, while $n$ is the safety factor. With these values, the maximum shear stress was determined as

$$
\begin{aligned}
\tau_{\max } & =81 \mathrm{MPa}, \\
\tau_{\max } & =\frac{1}{2} \sqrt{\sigma_{\max }^{2}+\tau^{2}} .
\end{aligned}
$$

From equations (2)-(5), $b$ and $h$ were calculated as $6 \mathrm{~mm}$ and $12 \mathrm{~mm}$, respectively.

\section{Design of the Handle}

Using the yield strength $\left(S_{y}\right) 324 \mathrm{MPa}$ of plain carbon steel AISI 1050 [5] and assuming that the pivoting pin can 


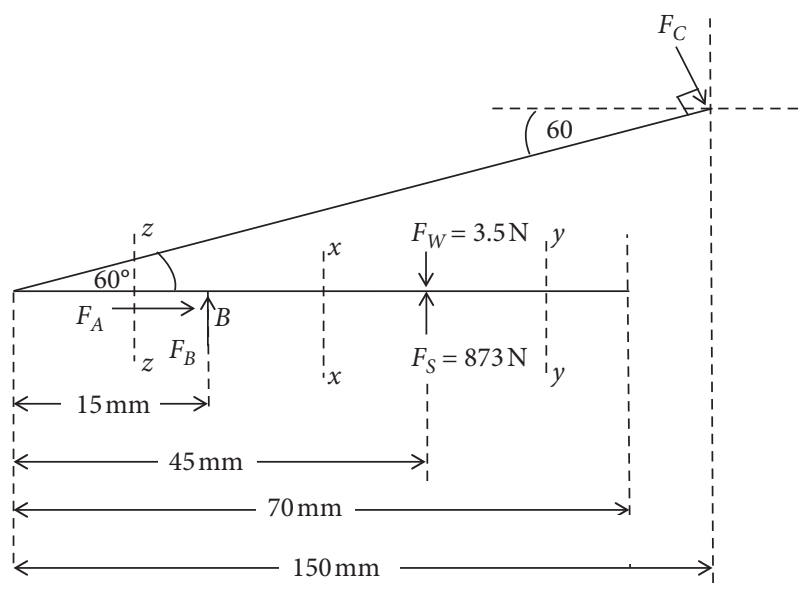

FIGURE 6: Free body diagram of the device in an operative mode.
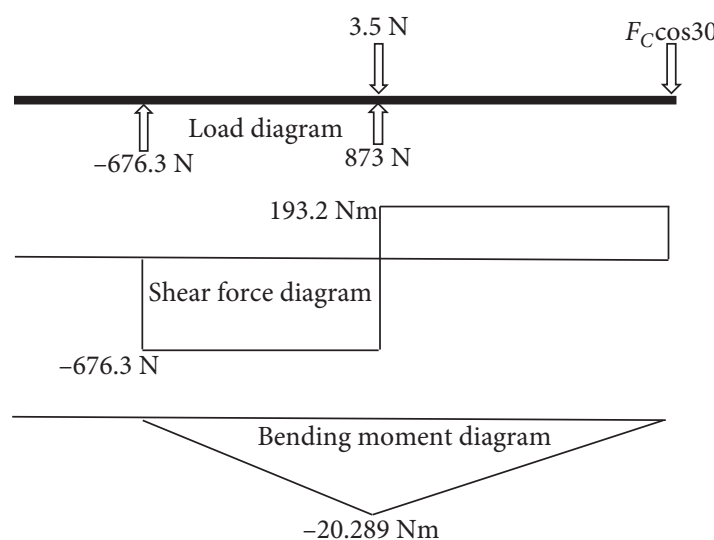

FIGURE 7: Load, shear force, and bending moment diagrams of the upper frame.

withstand the shear force, the handle was considered as a cantilever. The load, shear force, and bending moment diagrams of the handle are shown in Figure 8. The vertical component of the applied force $\left(F_{v}\right)$ and the bending moment $M_{o}$ of this force about the pivot region were computed as $334.632 \mathrm{~N}$ and $-86.937 \mathrm{Nm}$, respectively.

Maximum bending stress for the circular cross section $\left(\sigma_{c}\right)$ of the handle can be expressed as

$$
\sigma_{c}=\frac{32 M}{\pi \times d^{3}},
$$

where $d$ is the diameter of the handle.

From (6), the diameter of the handle was calculated as $18 \mathrm{~mm}$.

\section{Design of the Pivoting Pin}

High-strength low alloy steel with yield strength $\left(S_{y}\right)$ $310 \mathrm{MPa}$ was considered due to its high strength withstanding capabilities. To estimate the maximum bending stress and shear stress in the pin due to the applied force $\left(F_{C}\right)$, the load diagram with a shear force and bending

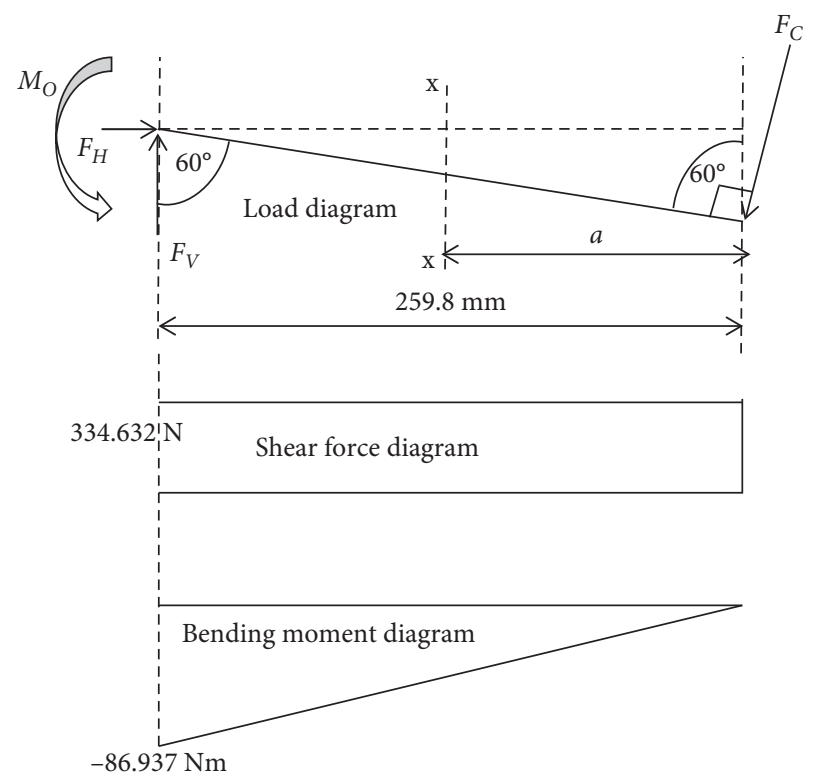

Figure 8: Load, shear force, and bending moment diagrams of the handle.

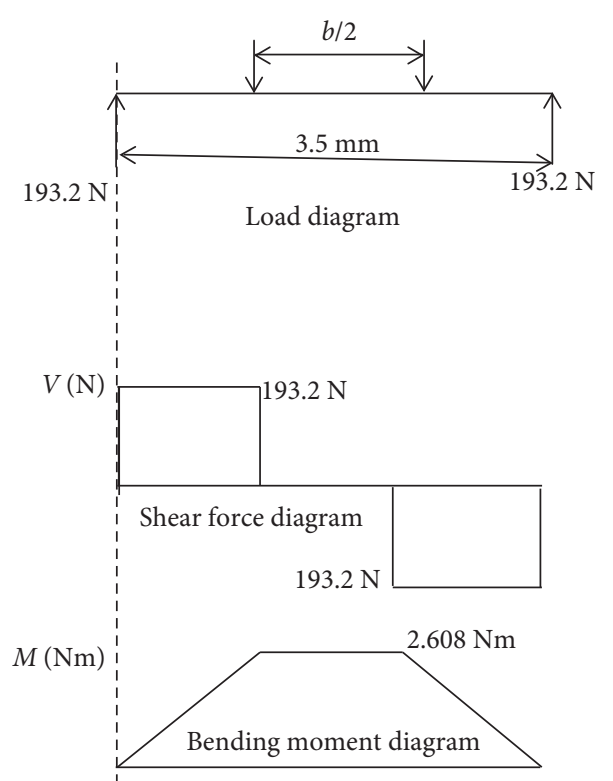

FIgURE 9: Load, shear force, and bending moment diagrams of the pivoting pin.

moment diagram of the pivoting pin as depicted in Figure 9 is used.

From (4), the maximum shear stress $\left(\tau_{\max }\right)$ was determined as $77.5 \mathrm{MPa}$. The diameter of the pin was then calculated to be $6 \mathrm{~mm}$ from equations (2)-(6).

\section{Magnetic Pull Force against Cotters Weight}

Magnetic pull force required to attract the cotters is given by

$$
F=0.58 B_{r}^{2} L_{m} \sqrt{A}
$$




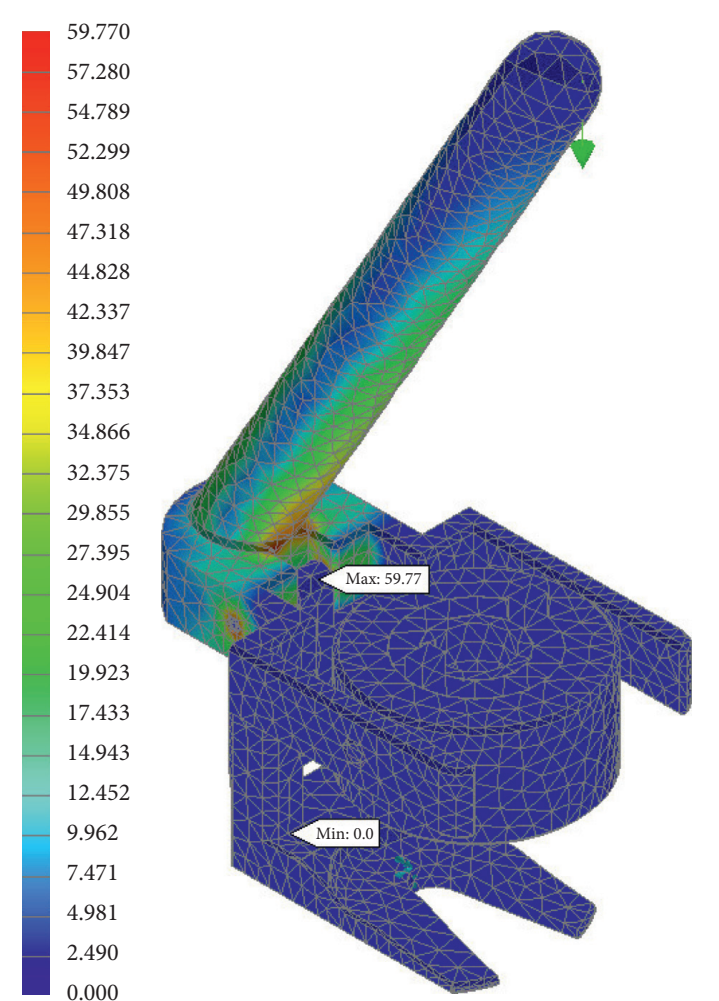

FIgURE 10: Simulation results showing von Mises stress.

where $F$ is the magnetic force, $B_{r}$ is the flux density, $L_{m}$ is the thickness of the magnet, and $A$ is the area of the magnet. A grade 1 ceramic material with a $B_{r}$ of 3850 Gauss was selected [4]. Considering a hollow disc area $(A)$,

$$
\begin{aligned}
& A=\pi(R-r)^{2}, \\
& A=6.25 \times 10^{-6} \mathrm{~m}^{2} .
\end{aligned}
$$

The magnetic pull force was then computed as $679.79 \mathrm{~N}$. This is capable of pulling off the cotters which have weights ranging from $5.689 \times 10^{-3} \mathrm{~N}-0.0276 \mathrm{~N}[6]$.

\section{Finite Element Analysis}

Finite element analysis (FEA) is a numerical tool, used for simulation of components and systems, to provide an accurate prediction of a component's response subjected to different kinds of loadings and boundary conditions [7].

A stress analysis was carried out on the device to ascertain the critical locations of stress concentration on it. The results show that the upper frame of the valve spring compressor experienced the highest von Mises stress of $59.77 \mathrm{MPa}$, which occurred at the neck region, as shown in Figure 10. Hence, attention was given to the upper frame, as it contained a critical stress concentration location [8]. Furthermore, the need to determine the fatigue life of the upper frame became necessary, so as to determine the extent to which the device can be used without the occurrence of fatigue failure.

Subsequently, fatigue analysis was carried out using an autodesk inventor. The analysis was first performed on the initial upper frame design. The result, as shown in Figure 11,

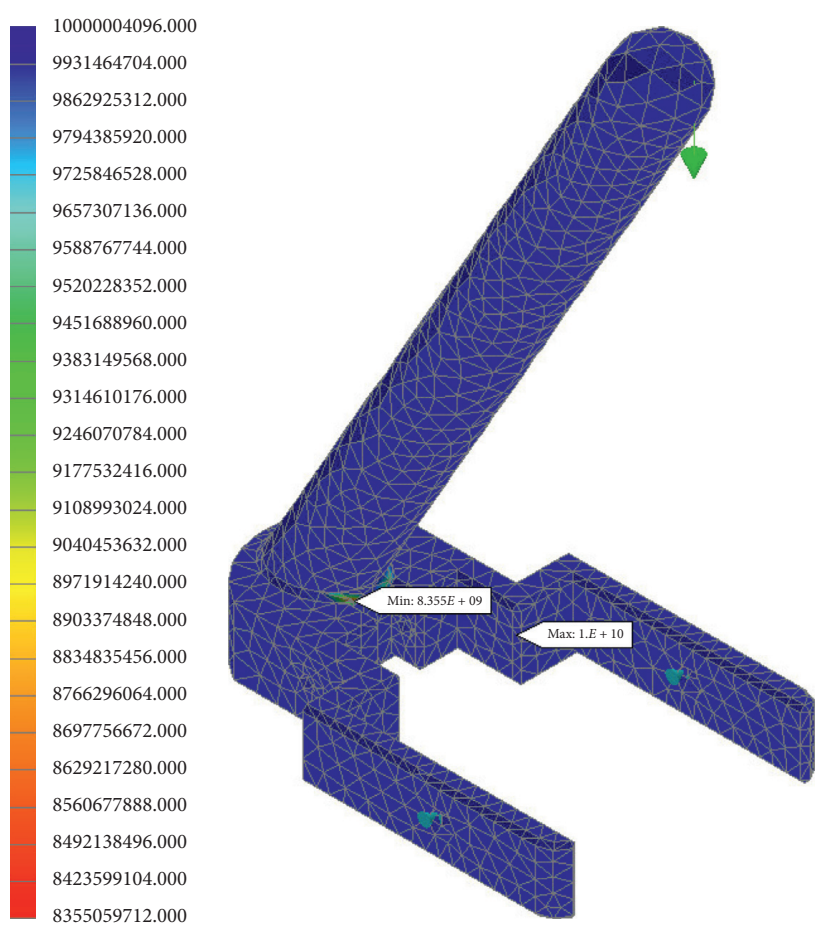

FIGURE 11: Simulation results showing fatigue life for the handle.

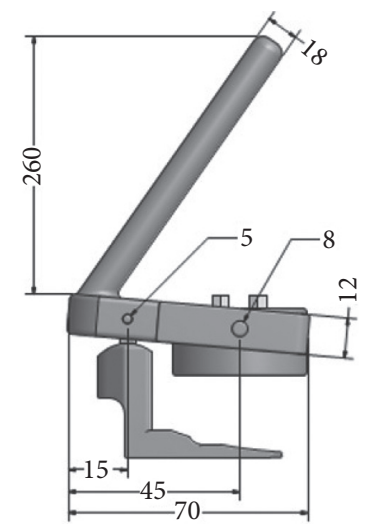

(a)

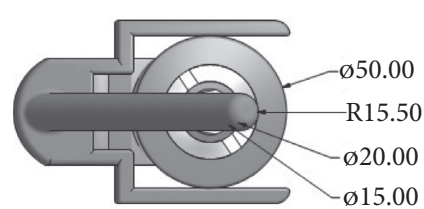

(c)

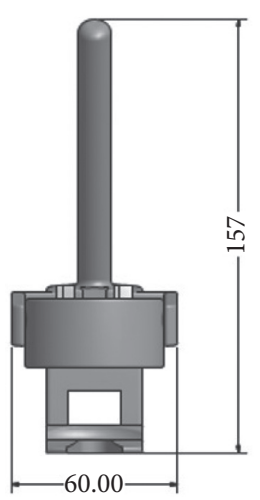

(b)

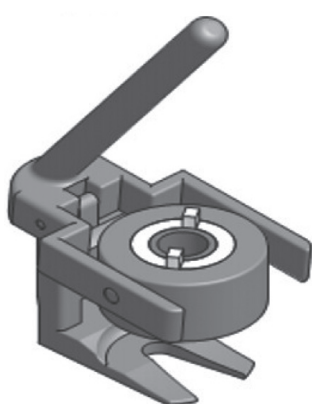

(d)
FIGURE 12: Projections of the poppet valve spring compressor. (a) Front view. (b) End view. (c) Plan. (d) Isometric view.

revealed that the handle will have a maximum fatigue life of $8.355 \times 10^{9}$, occurring at the neck region. This value is enough for safe and reliable operation of the tool. As according to 
Tareja [9], $10^{6}$ cycles is viewed as a large number of cycles and is often used to define the fatigue limit in metals.

The detailed drawing of the proposed valve spring compressor design is depicted in Figure 12.

\section{Conclusion}

A poppet valve spring compressor with a total mass of $0.88 \mathrm{~kg}$ has been designed. This tool employs a magnet with a pull force of $679.79 \mathrm{~N}$, which is capable of removing cotters within the weight range of $5.689 \times 10^{-3} \mathrm{~N}-2.76 \times 10^{-2} \mathrm{~N}$ during the dismantling of valve assembly. Finite element analysis (FEA) was used for the simulation of components and system. The stress analysis indicated that the upper frame of the valve spring compressor experienced the highest von Mises stress of $59.77 \mathrm{MPa}$ at the neck region, whilst the corresponding fatigue analysis showed a maximum fatigue life of $8.355 \times 10^{9}$.

\section{Data Availability}

The data for this research were based on field visits for first hand information.

\section{Conflicts of Interest}

The authors declare that they have no conflicts of interest.

\section{References}

[1] S. C. Mudd, Technology for Motor Mechanics, Gibrine Publishing Company, Accra, Gana, 2nd edition, 1972.

[2] Anon, "TWR engine componenets," 2012, http://www.trw-ec. com/en/products/productrange/valve-cotters/.

[3] W. W. Pulkrabet, Engineering Fundamentals of the Internal Combustion Engine, Pearson Education Inc., New York, NY, USA, 2011.

[4] Anon, "Valve spring diagnosis," 2013, http://www.aalacar. com/library/valvespringdiagnosis.htm.

[5] R. Budynas and K. Nisbett, Shegley's Mechanical Engineering Design, McGraw-Hill Compnies, New York, NY, USA, 8th edition, 2008.

[6] Anon, "Valve cotters," 2013, http://www.ms-motor-service. com/ximages/../x1ventilkegelenweb.pdf.

[7] Y. Yongyu, Y. Wei, Z. Weimin, C. Jiaming, C. Kang, and W. Daping, "The applications of finite element analysis in proximal," Computational and Mathematical Methods in Medicine, vol. 9, 2017.

[8] A. Erklig and M. A. Kütük, "Experimental finite element approach for stress analysis," Journal of Engineering, vol. 7, 2014.

[9] R. Talreja and J. Varna, Modeling Damage, Fatigue and Failure of Composite Materials, Woodhead Publishing, New York, NY, USA, 2016. 